\title{
Inhibitory Effect of Vitamin E Administration on the Progression of Liver Regeneration Induced by Partial Hepatectomy in Rats
}

\author{
Cristina Trejo-Solís, Victoria Chagoya de Sánchez, Alberto Aranda-Fraustro, \\ Lourdes Sánchez-Sevilla, Celedonio Gómez-Ruíz, and Rolando Hernández-Muñoz
}

Departamento de Biología Celular (CT-S, VCdS, AA-F, LS-S, CG-R, RH-M), Instituto de Fisiología Celular, Universidad Nacional Autónoma de México, Mexico

\begin{abstract}
SUMMARY: We have proposed that controlled peroxidative modifications of membranes could be playing a role in the early steps of liver regeneration. Hence, lipid peroxidation (LP) was modified in vivo by treatment with vitamin $E$ in rats subjected to partial hepatectomy $(\mathrm{PH})$, and its influence on liver regeneration was evaluated. Our results, using several methods to monitor LP, indicate that vitamin $E$ administration promoted a decreased LP rate in liver subcellular membranes. Vitamin $E$ drastically diminished cytosolic LP, shifting earlier increased LP in plasma membranes, and promoted a higher increase of nuclear LP in animals subjected to $\mathrm{PH}$. Pretreatment with vitamin E induced a striking reduction of liver mass recovery and nuclear bromodeoxyuridine labeling (clearly shown at 24 hours after surgery), as well as promoted a decreased expression of cyclin D1 and of the proliferating cell nuclear antigen after $\mathrm{PH}$. These effects seem to lead to a decreased mitotic index at 48 hours after $\mathrm{PH}$. Vitamin E pretreatment also diminished $\mathrm{PH}$-induced hypoglycemia but elevated serum bilirubin level, which was not observed in $\mathrm{PH}$ animals without vitamin treatment. In conclusion, an enhanced but controlled LP seems to play a critical role during the early phases of liver regeneration. Decreasing magnitude or time course of the PH-promoted enhanced LP (at early post-PH stages) by in vivo treatment with vitamin $\mathrm{E}$ could promote an early termination of preparative cell events, which lead to the replicative phase, during $\mathrm{PH}$-promoted liver proliferation. The latter could have a significant implication in the antitumorigenic effect ascribed to the treatment with vitamin E. (Lab Invest 2003, 83:1669-1679).
\end{abstract}

$R$ egenerating liver after partial hepatectomy $(\mathrm{PH})$ has been reported to have an increased antioxidant capacity, leading to minimal peroxide values when mitosis is maximal in the remnant liver (Wolfson et al, 1956). Indeed, lipid peroxidation (LP) inversely correlates with the rate of mitosis in several tissues and cell types (Burdon and Gill, 1990; Cheeseman et al, 1986a; Masotti et al, 1988).

Although the early phase of liver regeneration has been associated with a transient enhancement of liver mitochondrial LP and production of reactive oxygen species (ROSs) (Guerrieri et al, 1999; Tsai et al, 1992), discrepancies have emerged regarding LP status during compensatory liver cell proliferation induced by $\mathrm{PH}$. Indeed, increased LP has been found in liver homogenates from regenerating liver (Lambotte et al, 1989; Ueda et al, 1983), despite the fact that necrotic or apoptotic hepatocytes have not been observed at

\section{DOI: 10.1097/01.LAB.0000095688.89364.BF}

Received August 25, 2003.

Supported by a grant from Programa de Apoyo a Estudiantes de Posgrado of Universidad Nacional Autónoma de México (to CT-S) and partially supported by a grant from PAPIIT (IN-224401).

Address reprint requests to: Dr. Rolando Hernández-Muñoz, Departamento de Biología Celular, Instituto de Fisiología Celular, Universidad Nacional Autónoma de México (UNAM), Apdo. Postal 70-243, México 04510,D.F., México.E-mail: rhernand@ifc.unam.mx the onset of the proliferating liver (Oikawa and Novikoff, 1995). In addition, no changes in events characterizing the onset of mitochondrial permeability transition have been noticed in the regenerating liver (Guerrieri et al, 2002), and mitochondrial oxidative and phosphorylative activities are largely increased in $\mathrm{PH}$ rats (Hernández-Muñoz et al, 2003).

In a previous communication (Aguilar-Delfín et al, 1996) trying to settle this controversy, we showed that LP occurred during $\mathrm{PH}$-induced liver regeneration. Increased LP was confined to the plasma membrane and cytoplasmic fractions and correlated well with the magnitude of hepatic mass loss. Hence, we proposed that controlled peroxidative modifications of membranes could be playing a role in the early steps of liver regeneration (Aguilar-Delfín et al, 1996). In the same context, increased and selective LP could indeed participate in the compensatory gastric mucosal proliferation, which follows an ethanol-induced model of chronic gastric mucosal injury (Hernández-Muñoz et al, 2000).

The level of intracellular antioxidants could play a crucial role in regulating LP rate in the regenerating liver. Plasma membranes from regenerating liver have an increased content of lipid-soluble chain-breaking antioxidants, such as $\alpha$-tocopherol (Slater et al, 1990). An analogous situation has been observed to occur in active proliferating liver tumors (Cheeseman et al, 1986a). 
Dietary vitamin E seems to enhance liver regeneration many days after $\mathrm{PH}$ but not during the period between 3 to 6 days after surgery, suggesting a beneficial effect of antioxidants following PH (Gavino et al, 1985). However, treatment with $\alpha$-tocopherol prior to $\mathrm{PH}$ had no such stimulatory effect on $\mathrm{PH}$ and, rather, vitamin $\mathrm{E}$ tended to decrease the thymidine uptake by proliferating hepatocytes (Lambotte et al, 1989). In addition, the finding that vitamin $E$ protects liver tissue against oxidant stress and suppresses the tumorigenic potential of c-myc oncogene (Factor et al, 2000) would also support that pro-oxidant status can influence the $\mathrm{PH}$-induced proliferative response, because oxidant stress-derived LP may initiate a general cell response involving activation of transcriptional factors. Actually, cytokine-activable hepatocyte DNA binding proteins, including nuclear factor NF- $\mathrm{B}$ and signal transducers and activators of transcription (STAT) proteins, could be potential targets for ROS actions (Akira et al, 1990; Ruff-Jamison et al, 1994).

Therefore, the present study was aimed at assessing whether treatment with dietary concentrations of vitamin $\mathrm{E}$ prior to $\mathrm{PH}$ in rats modifies the compensatory liver hyperplasia induced by the surgery. The results strongly suggest that vitamin $E$ treatment of rats subjected to $\mathrm{PH}$ readily delays liver regeneration induced by $\mathrm{PH}$, probably by an inappropriate synchronizing of the preparative changes that occur in the replicative phase in this experimental model of liver regeneration.

\section{Results}

\section{Liver LP in Animals Subjected to PH and Treated with Vitamin $E$}

LP parameters were measured in five subcellular fractions obtained by differential centrifugation at several post-PH stages in animals with and without pretreatment with vitamin $\mathrm{E}$. As shown in Figure 1, pretreatment with vitamin E significantly decreased LP (thiobarbituric acid reactive substance [TBARS] content) in liver microsomal and nuclear fractions from shamoperated animals, whereas plasma membranes and cytosolic fractions were not significantly affected (time zero, Fig. 1). The $\mathrm{PH}$-induced increase of TBARS content was mainly found in plasma membranes and cytosolic fractions (Fig. 1). PH promoted an early sharp LP peak in plasma membranes (3 hours), followed by a substantial enhancement reaching a peak 24 hours after surgery. Treatment with vitamin $\mathrm{E}$ to $\mathrm{PH}$ rats completely blocked the early LP peak (3 hours), whereas the further $\mathrm{PH}$-induced increase in plasma membranes (12 hours after $\mathrm{PH}$ ) was not affected by vitamin $\mathrm{E}$ administration. However, the vitamin $\mathrm{E}$ abolished the 24-hour LP peak in animals subjected to $\mathrm{PH}$ (Fig. 1A). Cytosolic TBARS production (maximum peak 12 hours after $\mathrm{PH}$; Fig. 1B) was readily lowered in magnitude but maintained a similar time course in $\mathrm{PH}$ rats treated with vitamin $E$ (Fig. 1B). Microsomal LP was decreased at early $\mathrm{PH}$ times as previously found (Aguilar-Delfín et al, 1996; Slater et al, 1990). Vitamin E treatment of these animals promoted a drastic de-

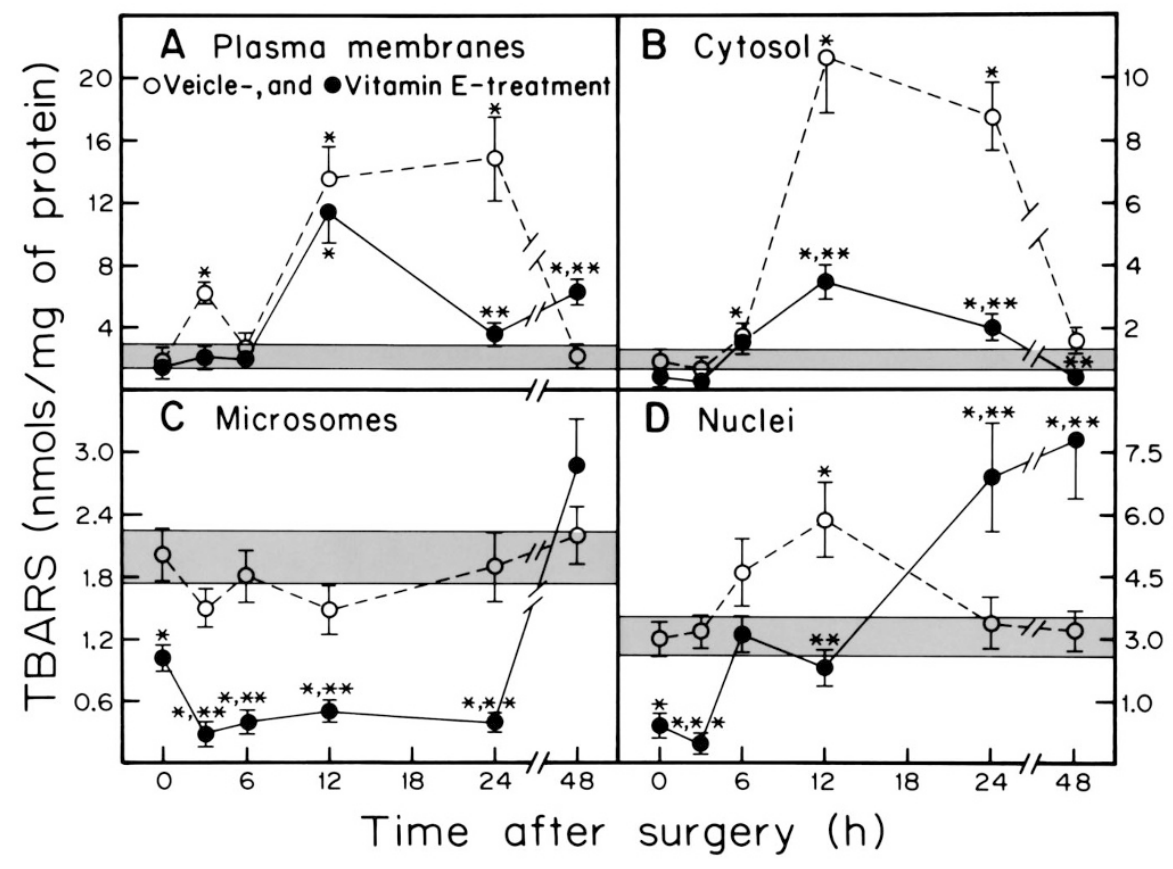

Figure 1.

Thiobarbituric acid reactive substance (TBARS) levels in subcellular liver fractions obtained from rats subjected to partial hepatectomy (PH) and treated with vitamin E. Results are the mean \pm SE of six individual determinations for each time per experimental group. Control values (sham-operated + oil vehicle) throughout the experimental times are showed by a shaded bar in each panel. Symbols for the experimental groups are indicated at the top of A. Sham-operated rats treated with vitamin $\mathrm{E}$ presented lower basal levels of TBARS in microsomal and nuclear fractions (indicated as time zero). Statistical significance as follows: ${ }^{*} p<0.01$ against sham-operated (control) group; ${ }^{* \star} p<0.01$ vs the $\mathrm{PH}+$ vehicle (peanut oil) group. 
crease in microsomal TBARS levels along the first 24 hours after $\mathrm{PH}$. At later times (48 hours after $\mathrm{PH}$ ), vitamin $\mathrm{E}$ did not affect this parameter (Fig. 1C). In addition, although vitamin $E$ readily decreased the rate of nuclear LP (ie, 12 hours after surgery), a significant increase of nuclear LP $(p<0.01)$ was recorded at later times after $\mathrm{PH}$ (24 to 48 hours) (Fig. 1D). Mitochondrial TBARS levels were not affected by either $\mathrm{PH}$ or by treatment with vitamin $\mathrm{E}$, throughout the times studied after $\mathrm{PH}$ (not shown).

Table 1 depicts variations of liver LP rate, as assessed by membrane conjugated dienes, as a function of $\mathrm{PH}$ and vitamin $\mathrm{E}$ administration. Unexpectedly, the amount of conjugated dienes in plasma membranes was higher in the vitamin E-treated group of $\mathrm{PH}$ animals than in those only subjected to surgery without prior vitamin $\mathrm{E}$ administration. $\mathrm{PH}$ did not modify mitochondrial conjugated dienes except for their transient decrease at 12 hours after surgery, whereas vitamin $E$ elicited a pronounced decrease in the amount of conjugated dienes during the first 48 hours after $\mathrm{PH}$ (Table 1). Although a microsomal amount of conjugated dienes was not significantly modified (not shown), both $\mathrm{PH}$ and vitamin $\mathrm{E}$ did change nuclear content of these LP-derived products. The $\mathrm{PH}$ induced changes in nuclear conjugated dienes showed a similar profile to that found for TBARS quantified in nuclei obtained from these animals (Fig. 1). Vitamin $E$ promoted a drastic increase in this parameter, as compared with both sham-operated and $\mathrm{PH}$ rats. Levels of nuclear conjugated dienes in $\mathrm{PH}$ rats receiving vitamin $\mathrm{E}$ was barely increased the first day after $\mathrm{PH}$ (Table 1).

Rats subjected to $\mathrm{PH}$ had lower rates of luminoldependent chemiluminescence in liver homogenates, mainly accounted for by low levels of free radical generation in both plasma membrane and microsomal fractions (Aguilar-Delfín et al, 1996). Administration of vitamin $\mathrm{E}$ to sham-operated rats induced a significant decrease of chemiluminescence in microsomes (assumed to be the main fraction containing the administered vitamin E) and in the other subcellular fractions tested (Fig. 2). In animals subjected to $\mathrm{PH}$ and treated with vitamin $\mathrm{E}$, decreased free radical-generated chemiluminescence was more evident when compared with the $\mathrm{PH}$ rats not treated with vitamin $\mathrm{E}$ (Fig. 2). As a whole, present data found in liver fractions from $\mathrm{PH}$ rats receiving vitamin $\mathrm{E}$ strongly suggest that pretreatment with the vitamin readily elicits an antioxidant response in these animals.

\section{Liver Content of $\alpha$-Tocopherol in Animals Treated with Vitamin $E$}

We found the expected increase of basal liver content of $\alpha$-tocopherol (nmols/mg of membrane's protein) in animals given repetitively vitamin $\mathrm{E}$ when compared with sham-operated and $\mathrm{PH}$ rats without vitamin $\mathrm{E}$ treatment (Table 2). After stopping pretreatment with vitamin $E$ in sham-operated rats, tocopherol levels gradually returned to those recorded in controls without vitamin treatment. Interestingly, after $\mathrm{PH}$ a clear decay of $\alpha$-tocopherol content was evident in the vitamin E-treated group, leading to nearly the content of $\alpha$-tocopherol found in nontreated rats subjected to $\mathrm{PH}$ (Table 2). In this latter group, a significant increase of $\alpha$-tocopherol was seen only 24 hours after surgery, and no significant differences were found in the liver $\alpha$-tocopherol content along the regenerative process, when comparing non-vitamin-treated $\mathrm{PH}$ rats to those treated with vitamin $E$ (Table 2). These results could suggest that liver $\alpha$-tocopherol metabolism was readily increased after $\mathrm{PH}$.

Table 1. Conjugated Dienes in Subcellular Fractions from PH Animals Treated with Vitamin E

\begin{tabular}{|c|c|c|c|}
\hline Fraction & Sham-operated $(+ \text { Vitamin } E)^{a}$ & $\mathrm{PH}+$ vegetable oil & $\mathrm{PH}+$ vitamin $\mathrm{E}$ \\
\hline Time after surgery & \multicolumn{3}{|c|}{$\Delta 233 \mathrm{~nm} / \mathrm{mg}$ of protein } \\
\hline \multicolumn{4}{|l|}{ Plasma membranes } \\
\hline 0 hours & $1.2 \pm 0.2[1.0 \pm 0.2]$ & - & - \\
\hline 6 hours & $1.3 \pm 0.2[0.9 \pm 0.1]$ & $1.0 \pm 0.2$ & $0.8 \pm 0.1$ \\
\hline 12 hours & $1.0 \pm 0.2[1.1 \pm 0.2]$ & $3.2 \pm 0.4^{*}$ & $5.4 \pm 0.9^{\star, * *}$ \\
\hline 24 hours & $1.4 \pm 0.2[1.0 \pm 0.2]$ & $4.9 \pm 0.9^{*}$ & $3.7 \pm 0.6^{*}$ \\
\hline \multicolumn{4}{|l|}{ Mitochondria } \\
\hline 0 hours & $1.0 \pm 0.1[0.3 \pm 0.1]^{*}$ & - & - \\
\hline 6 hours & $1.1 \pm 0.2[0.4 \pm 0.1]^{*}$ & $0.9 \pm 0.1$ & $0.2 \pm 0.04^{*, * *}$ \\
\hline 12 hours & $0.9 \pm 0.2[0.4 \pm 0.1]^{*}$ & $0.7 \pm 0.1$ & $0.3 \pm 0.05^{\star, * *}$ \\
\hline 24 hours & $1.2 \pm 0.2[0.3 \pm 0.1]^{*}$ & $0.9 \pm 0.2$ & $0.2 \pm 0.04^{*, * *}$ \\
\hline \multicolumn{4}{|l|}{ Nuclei } \\
\hline 0 hours & $1.0 \pm 0.1[0.3 \pm 0.1]^{*}$ & - & - \\
\hline 6 hours & $1.2 \pm 0.2[0.4 \pm 0.1]^{*}$ & $1.2 \pm 0.2$ & $0.6 \pm 0.1^{*, * *}$ \\
\hline 12 hours & $1.1 \pm 0.2[0.5 \pm 0.1]^{*}$ & $1.4 \pm 0.2$ & $0.4 \pm 0.1^{\star, \star *}$ \\
\hline 24 hours & $1.2 \pm 0.2[0.5 \pm 0.1]^{*}$ & $0.9 \pm 0.1$ & $1.3 \pm 0.15^{\star, \star *}$ \\
\hline
\end{tabular}

$\mathrm{PH}$, partial hepatectomy.

${ }^{a}$ Brackets indicate levels of conjugated dienes in subcellular fractions from sham-operated rats receiving vitamin $E$.

${ }^{*} p<0.01$ against the sham-operated group.

${ }^{* *} p<0.01$ vs the $\mathrm{PH}+$ vehicle (peanut oil) group. 


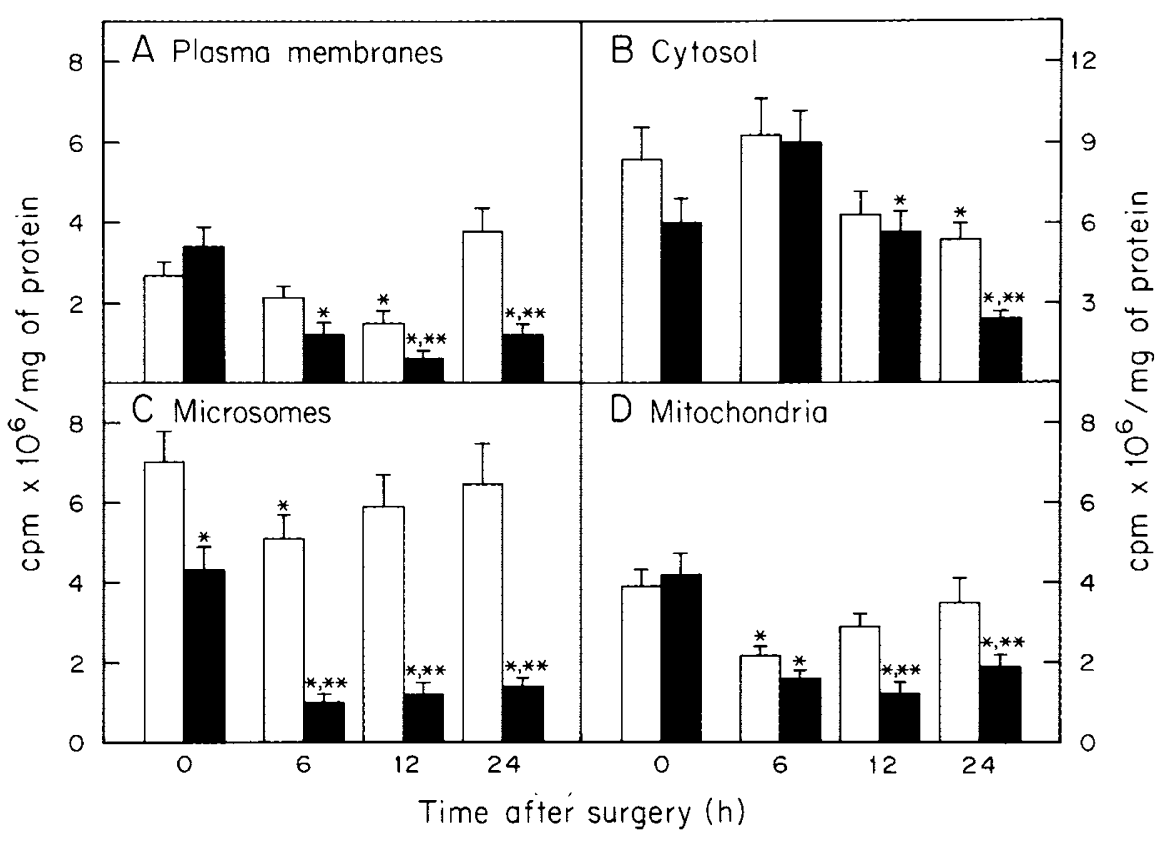

Figure 2.

Rate of chemiluminescence in subcellular fractions from partial hepatectomy $(\mathrm{PH})$ animals treated with vitamin $\mathrm{E}$. Results are the mean \pm SE of six individual determinations for each time per experimental group for luminol-dependent chemiluminescence in fractions from sham-operated and hepatectomized rats without (empty bars) or receiving vitamin $\mathrm{E}$ (solid bars). Time zero is the comparison of sham-operated rats receiving vitamin $\mathrm{E}$, against those receiving only the vehicle (controls). Statistical significance as follows: ${ }^{*} p<0.01$ against sham-operated (control) group; ${ }^{*} p<0.01$ vs the $\mathrm{PH}+$ vehicle (peanut oil) group.

Table 2. Liver Content of $\alpha$-Tocopherol in Membranes of Total Homogenates and Serum Metabolites in Animals Subjected to PH and Treated with Vitamin E

\begin{tabular}{|c|c|c|c|c|}
\hline \multirow[b]{2}{*}{ Time after surgery } & \multicolumn{4}{|c|}{ Experimental groups ${ }^{a}$} \\
\hline & Sham + vehicle & Sham + vitamin $\mathrm{E}$ & $\mathrm{PH}+$ vehicle & $\mathrm{PH}+$ vitamin $\mathrm{E}$ \\
\hline \multicolumn{5}{|c|}{ Liver $\alpha$-tocopherol ${ }^{b}$ (nmols/mg of membrane protein) } \\
\hline 0 hours & $28.2 \pm 3.1$ & $43.7 \pm 3.9^{*}$ & $27.6 \pm 2.7$ & $41.9 \pm 4.6^{\star, \star \star}$ \\
\hline 24 hours & $25.3 \pm 2.8$ & $39.5 \pm 3.6^{\star}$ & $20.8 \pm 2.4$ & $14.9 \pm 2.3^{\star, \star \star}$ \\
\hline 48 hours & $31.2 \pm 3.2$ & $37.5 \pm 3.1$ & $14.8 \pm 1.9^{*}$ & $19.4 \pm 2.8^{*}$ \\
\hline 72 hours & $29.6 \pm 3.0$ & $35.3 \pm 3.4$ & $30.0 \pm 4.1$ & $29.3 \pm 3.8$ \\
\hline \multicolumn{5}{|l|}{ Glucose (mg/dL) } \\
\hline 0 hours & $124 \pm 10$ & $113 \pm 9$ & $120 \pm 12$ & $103 \pm 10$ \\
\hline 12 hours & - & - & $81 \pm 6^{\star}$ & $56 \pm 7^{*, \star *}$ \\
\hline 24 hours & - & - & $71 \pm 8^{*}$ & $102 \pm 10^{\star *}$ \\
\hline 48 hours & - & - & $93 \pm 8^{*}$ & $106 \pm 11$ \\
\hline \multicolumn{5}{|l|}{ Total bilirubin $(\mathrm{mg} / \mathrm{dL})$} \\
\hline 0 hours & $0.6 \pm 0.1$ & $0.4 \pm 0.1$ & $0.5 \pm 0.1$ & $0.4 \pm 0.1$ \\
\hline 12 hours & - & - & $0.9 \pm 0.2$ & $0.7 \pm 0.1$ \\
\hline 24 hours & - & - & $0.6 \pm 0.1$ & $0.7 \pm 0.2$ \\
\hline 48 hours & - & - & $0.6 \pm 0.1$ & $2.2 \pm 0.3^{\star \star \star *}$ \\
\hline
\end{tabular}

$\mathrm{PH}$, partial Hepatectomy.

${ }^{a}$ Results are expressed as mean \pm SE of five individual determinations per experimental time.

${ }^{b} \alpha$-Tocopherol was determined through HPLC and serum metabolites by diagnostic kits.

${ }^{*} p<0.01$ vs sham-operated group.

${ }^{\star *} p<0.01$ vs the $\mathrm{PH}+$ vehicle (oil) group.

\section{Effect of Vitamin $E$ on the Progression of Liver Regeneration Induced by $\mathrm{PH}$}

We evaluated the effect of the antioxidant action of vitamin $\mathrm{E}$ in the progression of liver regeneration after $\mathrm{PH}$ as assessed by several parameters. Rats subjected to $\mathrm{PH}$ showed a gradual increase of cell nuclear labeling after in vivo administration of bromodeoxyuri- dine (BrdU), reaching a maximal peak 48 hours after surgery (6- to 8-fold more than controls), which declined thereafter (Fig. 3A). However, when PH rats were treated with vitamin $\mathrm{E}$ prior to surgery, a decreased cell proliferation as estimated by BrdU incorporation was noted 24 hours after PH (Fig. 3A). Nonetheless, nuclear BrdU labeling was as high as in 


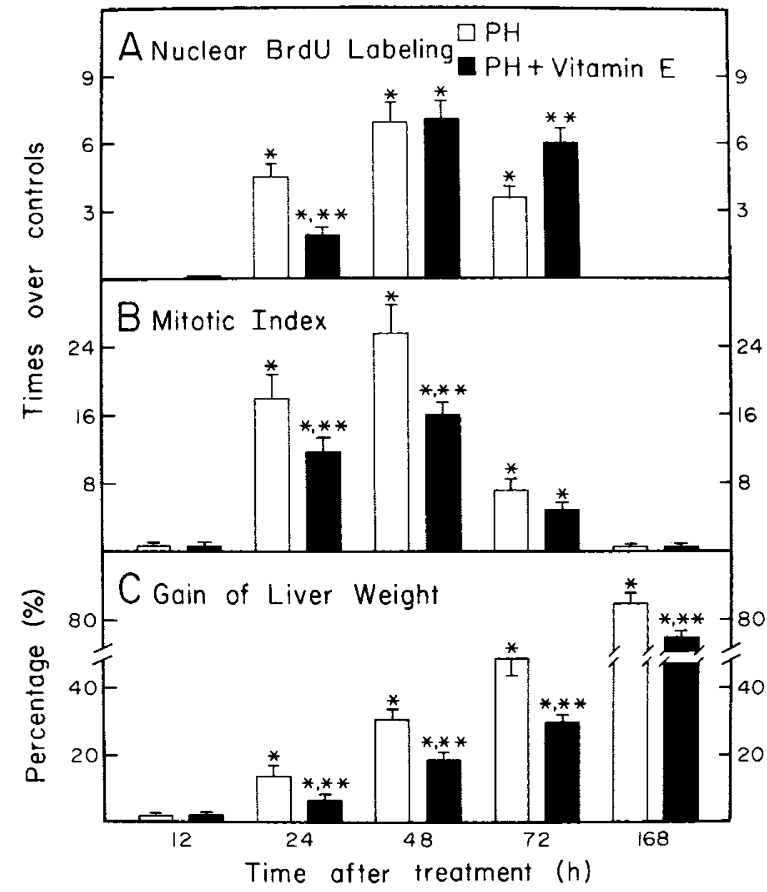

Figure 3.

Effect of partial hepatectomy $(\mathrm{PH})$ and treatment with vitamin $\mathrm{E}$ on parameters indicative of liver regeneration. Results are the mean \pm SE of five individual determinations for each experimental point, and expressed as times over controls for nuclear bromodeoxyuridine (BrdU) labeling (0.07 of $\Delta \mathrm{A}[490$ $\mathrm{nm}] / \mu \mathrm{g}$ of nuclear protein; panel $\mathrm{A})$, and for the mitotic index $(0.3 \pm 0.1$ mitotic cells per field of 10 fields examined by a microscopic $\times 40$ objective; panel B). (C) The recovery of the initial mass in function of time after surgery is shown. Experimental groups as indicated by symbols (A). Statistical significance as follows: ${ }^{*} p<0.01$ against sham-operated (control) group; ${ }^{* *} p$ $<0.01$ vs the $\mathrm{PH}+$ vehicle (peanut oil) group.

controls 2 days after $\mathrm{PH}$ and even remained significantly augmented in animals treated with vitamin $\mathrm{E} 72$ hours after surgery (Fig. 3A). A good correlation was obtained with the rate of the mitotic index obtained in liver samples from the experimental groups. Abundant mitotic images were recorded within 24 to 48 hours after $\mathrm{PH}$, which decreased rapidly to be absent 7 days after surgery (Fig. 3B). On the contrary, rats subjected to $\mathrm{PH}$ and administered with vitamin $\mathrm{E}$ showed a reduced mitotic activity during all of the times tested (Fig. 3B). In addition, although vitamin E was withdrawn 24 hours before starting the experiments, its effect on cell cycle was long-lasting as reflected by the deficient recovery of liver mass, even 7 days after surgery (92 \pm 7 versus $73 \pm 7 \%$ of recovered liver mass in control hepatectomized rats, and in those receiving the vitamin, respectively) (Fig. $3 C$ ).

The effect of vitamin $E$ on altering the transition between $G_{1}$ and $S$ phases in rats subjected to $P H$ was further confirmed by immunohistochemical identification of proliferating cell nuclear antigen (PCNA) expression in proliferating liver cells (Fig. 4). Liver specimens taken from sham-operated rats without (Fig. 4A-1) or with vitamin $\mathrm{E}$ pretreatment (Fig. 4A-2) did not show any PCNA-positive liver cells. At 24 hours after $\mathrm{PH}$, the proliferating liver depicted a wide immunopositivity for the nuclear presence of PCNA protein, which was observed in most of the liver cells (Fig. 4A-3). However, animals subjected to $\mathrm{PH}$ and treated with vitamin E clearly showed a decreased PCNA expression at 24 hours after surgery. Nuclear amount of PCNA, quantified by Western blot assays, showed the same profiles with either $\mathrm{PH}$ or vitamin $\mathrm{E}$ administration. $\mathrm{PH}$ induced a progressive enhanced PCNA expression starting at 6 hours and reaching a maximal peak at 24 hours after surgery (Fig. 4B), being practically normalized at 48 hours after $\mathrm{PH}$ (not shown). Interestingly, vitamin $\mathrm{E}$ treatment elicited a significant higher basal PCNA expression (as compared with $\mathrm{PH}$-only animals), which was also readily stimulated by $\mathrm{PH}$ in these rats (Fig. 4B). Again, at 24 hours after surgery, PCNA was suddenly diminished in $\mathrm{PH}$ rats receiving vitamin $\mathrm{E}$ (Fig. 4B).

Moreover, expression of cyclin D1, another reliable marker of G1 phase in the cell cycle, presented a similar shifted pattern induced by treatment with vitamin E (Fig. 5). Rats subjected to PH had a progressive increased expression of cyclin D1, starting 3 hours after surgery and peaking 12 hours after $\mathrm{PH}$. Whereas vitamin $\mathrm{E}$ significantly increased the basal cyclin D1 level, it also shifted earlier its maximal expression, which was noticed at 6 hours after surgery in liver nuclei obtained from $\mathrm{PH}$ animals pretreated with vitamin E (Fig. 5).

\section{Effect of Vitamin E on Serum Metabolites during Liver Regeneration Induced by $\mathrm{PH}$}

In a previous communication (Morales-González et al, 1999), we have reported that rat liver regeneration, after two-thirds $\mathrm{PH}$, occurs accompanied by characteristic changes in serum levels of some metabolites. Besides the well-known decrease of blood glucose, the level of triacylglycerols are increased without significant modifications in serum levels for albumin or bilirubin. Administration of vitamin $\mathrm{E}$ to $\mathrm{PH}$ rats elicited the opposite profile in the aforementioned parameters. The vitamin induced an early recovery of the $\mathrm{PH}$ promoted hypoglycemia but significantly increased bilirubin (Table 2).

\section{Discussion}

The putative involvement of oxygen free radicals and liver oxidant status in the onset and progression of $\mathrm{PH}$-induced liver regeneration remains an important issue, mainly due to the potential antioxidant therapeutics of chronic liver damage, such as liver tumor generation (Factor et al, 2000). In the present study, we show that selective LP occurring in the proliferating liver after PH (Aguilar-Delfín et al, 1996) was readily diminished by pretreatment with vitamin $\mathrm{E}$, resulting in an earlier appearance of some events associated with the replicative phase. However, these events culminated in a deficient recovery of the lost mass after $\mathrm{PH}$ and point to the importance of hepatic management of reactive oxygen species during cell proliferation.

It has been accepted that fatty acid peroxides exert an inhibitory effect on cell division in the remnant liver 

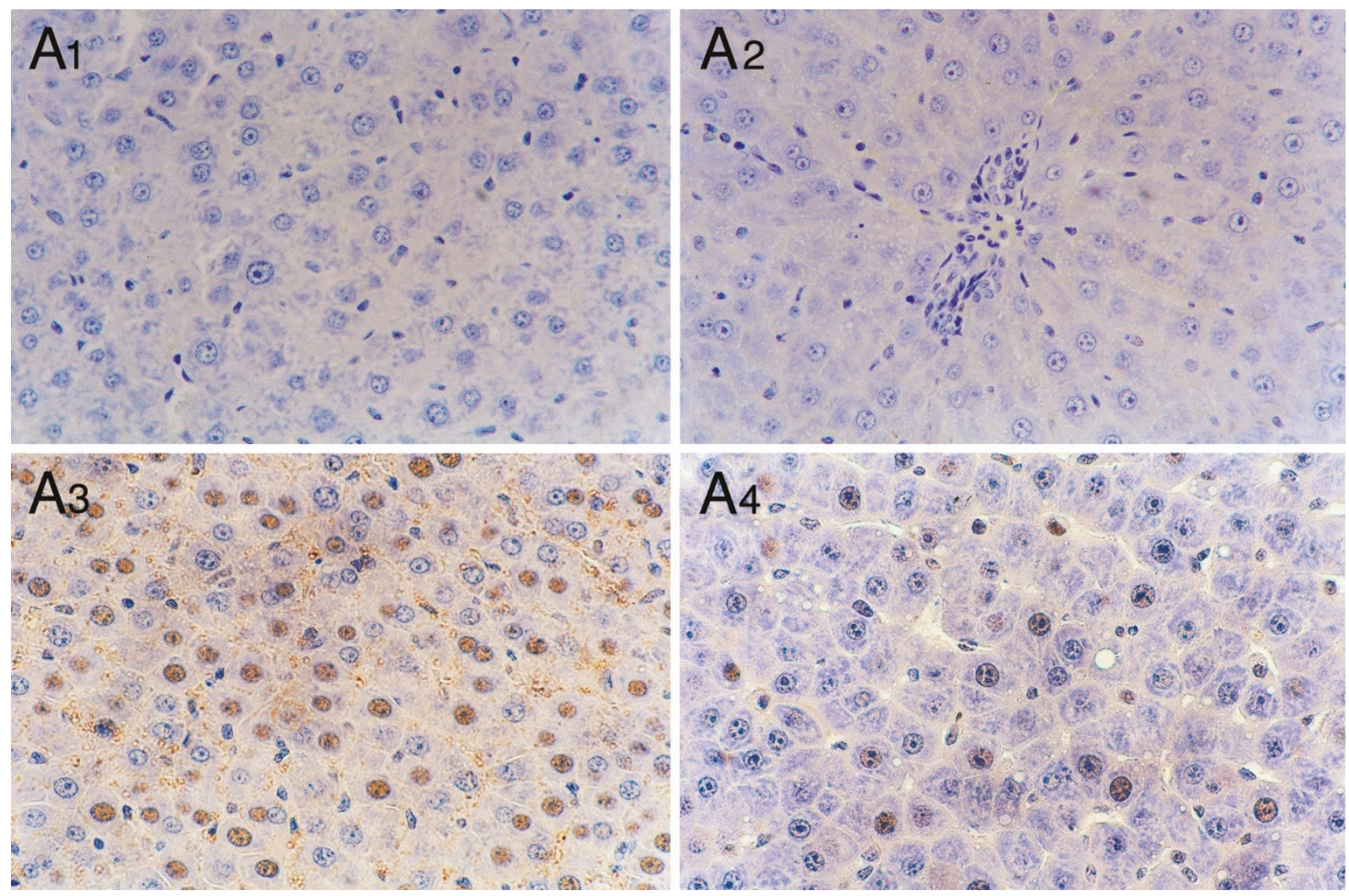

\section{Figure 4.}

Effect of partial hepatectomy $(\mathrm{PH})$ and treatment with vitamin $\mathrm{E}$ on liver expression of the proliferating cell nuclear antigen (PCNA). Representative histologic samples from sham-operated (A1), and hepatectomized rats, 24 hours after surgery (A3); and from sham-operated (A2), or PH animals pretreated with vitamin E at 24 hours (4) after surgery. PCNA-expressing cells were identified by a brown staining in the nuclei. Positive liver cells were examined in 10 fields examined by a microscopic $\times 40$ objective.

after PH (Wolfson et al, 1956). This finding has been corroborated in rapid proliferating tissues, where an enhanced antioxidant activity has been consistently reported (Cheeseman et al, 1988; Hammad et al, 1990). In addition, vitamin E ( $\alpha$-tocopherol) content has been identified as a major contributing factor in the decreased LP rate found in tumor cells (Borrello et al, 1985; Cheeseman et al, 1986a).

An in vitro correlation between vitamin E content and cell proliferation has already been described (Gavino et al, 1981). Previous reports indicate that the reduced microsomal LP rate coincides with an increased content of $\alpha$-tocopherol, and the latter is also associated in time with higher activity of thymidine kinase in livers obtained from $\mathrm{PH}$ rats (Cheeseman et al, 1986b; Slater et al, 1990). Increased LP content has been shown in the regenerating liver of rats maintained on a vitamin E-deficient diet, suggesting that vitamin $E$ plays a leading role in the defense system and that LP is largely concerned with liver regeneration (Tanaka et al, 1996). In addition, metallothioneins become induced following $\mathrm{PH}$, and their suppression produces a decreased rate in liver regeneration as measured by the expression of PCNA (Arora et al, 1998).

With the present model, increased LP occurs in the presence of normal or elevated levels of liver antioxidant defenses during $\mathrm{PH}$-induced liver regeneration
(Aguilar-Delfín et al, 1996; Arora et al, 1998; Gavino et al, 1981; Lambotte et al, 1989; Ueda et al, 1983). Despite the fact that a population of hepatocytes containing peroxisomes with no cytochemically demonstrable catalase activity has been identified in the regenerating liver, there is no evident oxidant stress leading to necrotic or apoptotic processes in liver cells (Oikawa et al, 1995). As a whole, these findings strongly indicate that enhanced LP occurs concomitantly with the onset of liver regeneration after $\mathrm{PH}$ in rats. Because it is not clear what mechanism or mechanisms underlying cell proliferation can be affected by LP, questions arise such as Is increased LP merely an adverse consequence of metabolic adjustment in the regenerating liver? or Is it a necessary event linked to the progression of cell cycle during liver regeneration? The present results seem to provide answers to the second one.

Dietary supplementation with $\alpha$-tocopherol decreases LP rate in normal rat liver membranes (microsomes, mitochondria, and in plasma membrane), and in the cytosol (Cheeseman et al, 1986b), without significantly modifying rate of $\mathrm{PH}$-induced liver regeneration (Gavino et al, 1985; Lambotte et al, 1989). Injection of superoxide dismutase to $\mathrm{PH}$ animals depresses ${ }^{3} \mathrm{H}$-thymidine incorporation into DNA 24 hours later (Lambotte et al, 1989), suggesting a dependence of $\mathrm{PH}$-induced liver regeneration on pro- 


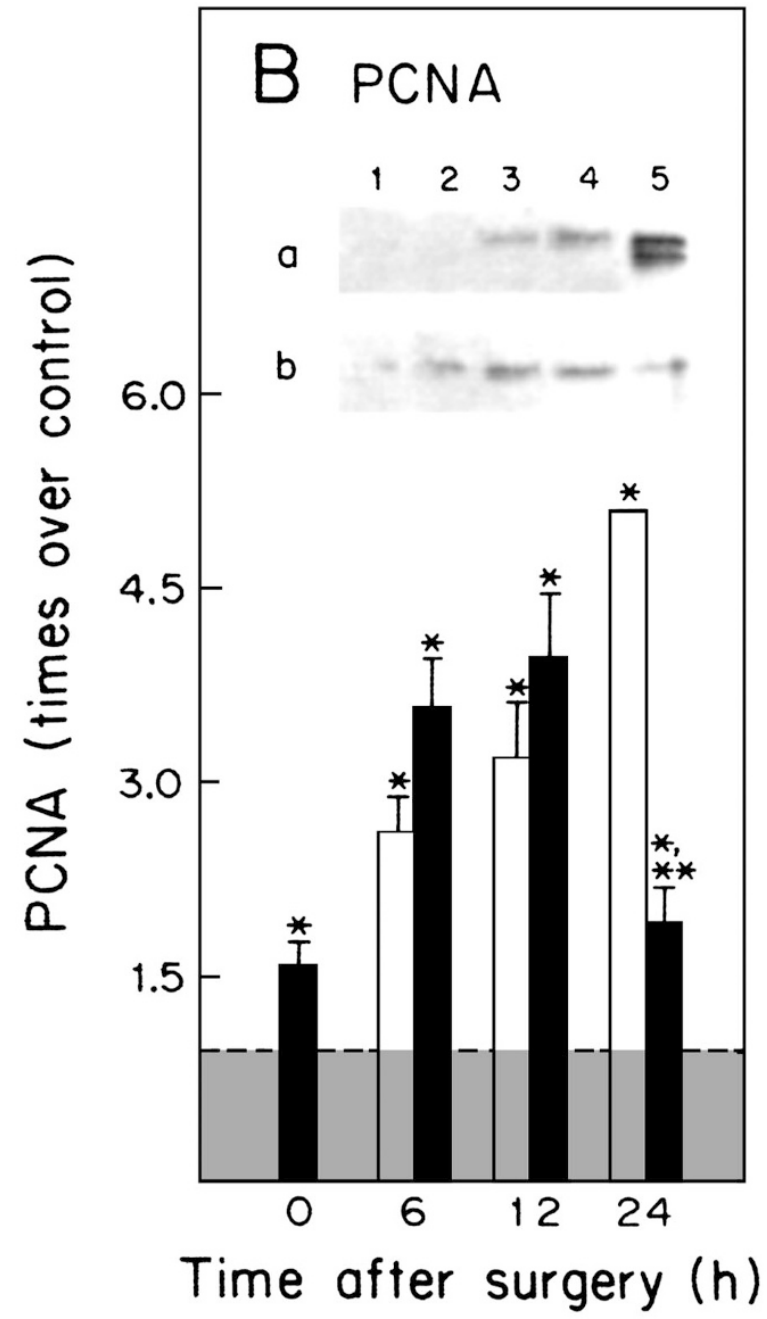

Figure 4.

(B) Western blot analysis for PCNA concentration. Inset: Representative analysis for PCNA in animals subjected to $\mathrm{PH}$ only (a), or those $\mathrm{PH}$ rats treated with vitamin $E(b)$. Lane 1: time zero $\left(25.1 \pm 4.2 \times 10^{3}\right.$ arbitrary units); Lane 2: 3 hours; Lane 3: 6 hours; Lane 4: 12 hours, and Lane 5: 24 hours after PH. Experimental groups as indicated by bars in Figures 1 and 2. Statistical significance as follows: ${ }^{\star} p<0.01$ against sham-operated (control) group; ${ }^{* \star} p$ $<0.01$ vs the $\mathrm{PH}+$ vehicle (peanut oil) group.

oxidant status. However, the need for increased LP to trigger or drive the compensatory liver hyperplasia after $\mathrm{PH}$ can be questioned, because administration of catalase, superoxide dismutase, or hepatic stimulator substance can improve $\mathrm{PH}$-induced rat liver regeneration (Fukuhara et al, 1999; Mao-Hua et al, 1993).

Present results indicate that vitamin $\mathrm{E}$ administration to rats elicited a reliable diminution of LP as assessed by TBARS, conjugated dienes, and chemiluminescence-detected ROS, an effect found bigger in some subcellular fractions (Figs. 1 and 2). The antioxidant effect of $\alpha$-tocopherol (vitamin E) was more evident in most tested subcellular fractions when luminol-dependent chemiluminescence was assayed (Fig. 2). With this assay, animals subjected to this antioxidant treatment and $\mathrm{PH}$ showed the same and sustained decrease of LP at several times after $\mathrm{PH}$ and correlated well with the initial decay of liver
A
1
2
3
4
5
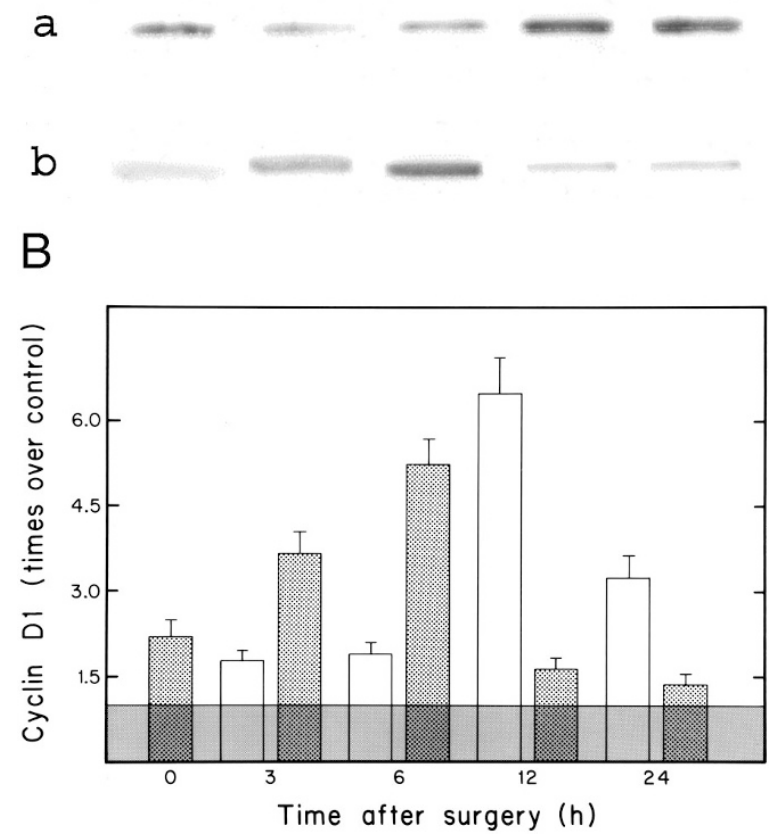

Figure 5.

Effect of partial hepatectomy $(\mathrm{PH})$ and treatment with vitamin $\mathrm{E}$ on liver expression of cyclin D1. (A) A representative Western blot analysis for cyclin D1 in animals subjected to PH only (a), or those $\mathrm{PH}$ rats treated with vitamin E (b). Lane 1: time zero; Lane 2: 3 hours; Lane 3: 6 hours; Lane 4: 12 hours; and Lane 5: 24 hours after PH. (B) Densitometric analysis of the blots depicted in A. Control animals ( $5.1 \pm 0.4 \times 10^{3}$ arbitrary units) are represented by the shadowed horizontal bar. Results are expressed as times over control for PH rats pretreated with oil (vitamin E vehicle, empty bars), or for those animals receiving vitamin $\mathrm{E}$ pretreatment.

$\alpha$-tocopherol content, which seemed to indicate an active vitamin consumption to maintain very low levels of lipid peroxides (Table 2). In $\mathrm{PH}$ rats, vitamin $\mathrm{E}$ partially blocked restoration of the liver mass and readily decreased the maximal peaks of nuclear BrdU labeling, PCNA immunostaining, and the mitotic index, shifting that of PCNA earlier during the prereplicative phase, characterized by a low rate of DNA synthesis (Figs. 3 and 4). Interestingly, pretreatment with vitamin $E$ induced a significantly increase of liver cyclin D1 levels prior to surgery (Fig. 5). The early increase in cyclin D1 mRNA, in response to mitogens and co-mitogens, is associated with accelerated onset of DNA synthesis (Pibiri et al, 2001); however, post-transcriptional regulation of cyclin D1 protein content, as well as the rate of ubiquitin-mediated proteolysis, also establish the level of the functional cyclin D1 protein (Awad and Gruppuso, 2000; Spinella et al, 1999). Then, vitamin $E$ administered in vivo could modify the liver content of cyclin D1 through these already mentioned mechanisms, but after $\mathrm{PH}$, the time course of cyclin D1 expression was significantly modified in the regenerating liver. Other events associated with the onset of $\mathrm{PH}$-induced liver regeneration (serum 
metabolites and enzyme activities) were also largely modified by administration of vitamin $\mathrm{E}$. Hence, in our conditions timing, magnitude, and even subcellular distribution of the lipoperoxidative events seem to be of major importance in the controlled progression of $\mathrm{PH}$-induced liver regeneration. Indeed, we believe that a controlled LP during $\mathrm{PH}$-induced liver regeneration could represent a synchronizing event probably signaling the response of early gene expression. Indeed, a synchronized early response (NF- $\kappa \mathrm{B}$ and STATs proteins) and immediate-early gene expression in liver regeneration induced by several surgical models (Laurent et al, 2001) have been shown.

$\mathrm{NF}-\kappa \mathrm{B}$ was first identified in the liver as a factor that is rapidly activated in hepatocytes after $\mathrm{PH}$ (Cressman et al, 1994). It is linked to TNF- $\alpha$ because defective liver regeneration has been found in TNF receptor knockout mice, which do not show hepatic induction of NF- $\kappa$ B after PH (Yamada et al, 1997). Therefore, the cytokine TNF- $\alpha$, the downstream signal NF- $\kappa \mathrm{B}$, and target genes like IL- 6 have important roles in protecting the liver from injury and restoring liver mass following toxic damage and hepatectomy (Taub, 1998).

Vitamin E has been shown to consistently inhibit cell proliferation and growth of several cell lines in culture, such as smooth muscle cells (Chatelian et al, 1993; Kunisaki et al, 1995). Its inhibitory effect has been postulated as independent from its antioxidant property, mainly associated with inhibition of PKC- $\alpha$ isoform activation, an effect mediated by dephosphorylation of this protein through activity of a specific phosphatase (Ricciarelli et al, 1998). However, the antioxidant properties of vitamin $\mathrm{E}$ could be more important in its antiproliferative action in hepatic cells. Administration of peroxisome proliferators induce lower hepatic vitamin E concentrations, increased lysosomal enzyme activities, and conjugated dienes accumulation, which correlate with the degree of liver carcinogenicity (Conway et al, 1989). Administration of vitamin $\mathrm{E}$ and other antioxidants in tumor-bearing animals reduce the amount of lipid peroxides and also inhibit proliferation of tumor cells (Yang et al, 1989). Moreover, the overexpression of $c-m y c$ and TGF- $\alpha$ promote increased production of reactive oxygen species; here, vitamin E supplementation decreases oxygen radical generation and stabilizes chromosomal and mtDNA in the liver (Factor et al, 2000). All this evidence has led to the proposal of an inverse association between liver concentrations of $\alpha$-tocopherol and the development of hepatic carcinogenesis.

The hypothesis that ratios between pro- and antioxidants agents could control the balance between apoptosis and cell division is being tested based on recent findings: oxidant stress-derived LP may initiate a general cell-responsive mechanism involving activation of transcriptional factors (Schreck and Baeuerle, 1991; Toyonuki et al, 1995). For instance, the transcriptional factor $\mathrm{HFH}-11$ expression is reactivated in proliferating hepatocytes during liver regeneration, probably as a response to oxidative stress (Ye et al, 1997). Furthermore, $\mathrm{H}_{2} \mathrm{O}_{2}$ selectively stimulates ex- pression of big MAP kinase I enzymatic activity in cell lines (Abe et al, 1996). In addition, LP by-products might induce the hepatocyte acute-phase response, including activation of nuclear factor NF- $\kappa \mathrm{B}$, signal transducers and activators of transcription proteins, and certain CCAAT/enhancer binding protein (C/EBP) isoforms, regulating transcription of hepatocytespecific genes (Akira et al, 1990; Ruff-Jamison et al, 1994).

Based on the observation that $\alpha$-tocopherol may contribute toward the maintenance of a critical balance between possible positive and negative effects of active oxygen species in active proliferating cells (Burdon and Gill, 1990), we propose that increased tissue content of vitamin $\mathrm{E}$ could break up this exquisite balance, shifting earlier preparative cell changes and promoting some kind of earlier termination of the known replicative phase during $\mathrm{PH}$-induced liver regeneration.

From these studies we expect to gain a clearer picture to evaluate the possible therapeutic use of vitamin $\mathrm{E}$ and other antioxidants prior to and following liver surgery and to assess them in the treatment of chronic liver diseases accompanied by a very poor regenerative response (cirrhosis). We have demonstrated that selective enhancement of LP is also associated with stimulation of liver cell proliferation rather than with hepatocellular damage (HernándezMuñoz et al, 1997).

\section{Materials and Methods}

\section{Animal Treatments}

Male Wistar rats weighing 240 to $280 \mathrm{~g}$ were fed ad libitum and maintained under a 12-hour light/dark cycle. Surgical procedures were performed between 9:00 and 10:00 am. Animals were divided in two groups: rats receiving a daily intragastric administration of $6 \mathrm{lU} / \mathrm{kg}$ of $\alpha$-tocopherol (Sigma Chemical Company, St. Louis, Missouri) diluted in peanut oil (1 $\mathrm{ml} / \mathrm{rat}$ ), and those receiving only the vitamin $\mathrm{E}$ vehicle. Treatments were applied for 3 days, and on the 4th day, animals received no treatment. On the 5th day, animals were subdivided for surgical treatment. A two-thirds $\mathrm{PH}$ was performed, according to Higgins and Anderson (1931). Sham-operated animals were subjected to laparotomy under ether anesthesia to provide a control for surgical conditions. Animals were killed after 3, 6, 12, 24, 48, or 170 hours after surgery by an ip lethal dose of sodium pentobarbital. Liver and blood were rapidly removed for the procedures described below. All manipulations were conducted in accordance to the Institutional Guide for Animal Experimentation and Care (National University of Mexico).

\section{Subcellular Fractionation of the Liver and Sampling of Other Organs}

To obtain high purity subcellular liver fractions (plasma membranes, mitochondria, microsomes, cytosol, and nuclei) from control or $\mathrm{PH}$-subjected rats, we followed 
the same protocol previously described in detail (Aguilar-Delfín et al, 1996). In addition, serum was obtained after centrifugation of total blood. When necessary, samples were stored at $-70^{\circ} \mathrm{C}$ until use.

\section{In Vivo BrdU Incorporation into Liver DNA}

To evaluate the rate of DNA synthesis in vivo, rats subjected to $\mathrm{PH}$ and those pretreated with vitamin $\mathrm{E}$ were ip injected with $250 \mathrm{mg} / \mathrm{kg}$ body weight of BrdU. Administration was carried out 12 hours before killing, livers removed, and nuclei were isolated as previously described (Aguilar-Delfín et al, 1996). Twenty $\mu \mathrm{g}$ of nuclear protein were applied in 96-well microtiterplate, and presence of BrdU was measured by a kit of cell proliferation ELISA (colorimetric), according the instructions from the manufacturer (Boehringer Mannheim, Germany). Results are expressed as $\Delta \mathrm{A}_{490}$ (absorbance) per milligram of nuclear protein.

\section{Analytical Procedures}

Determination of the amount of aldehydic products (TBARS) and conjugated dienes generated by LP, as well as detection of the produced free radicals by luminol-dependent chemiluminescence, were essentially done by the methods described elsewhere (Aguilar-Delfín et al, 1996). Vitamin E content in liver homogenates from control and $\alpha$-tocopherol-treated animals was determined through high-pressure liquid chromatography, according to the method described by Huang and Shaw (1994).

\section{Liver Histology}

Liver samples fixed in buffered 10\% formaldehyde $(\mathrm{pH}$ 7.4) were embedded in wax, cut, and stained with hematoxylin-eosin. Mitotic index was estimated in these preparations with an optical microscope (Olympus, $\mathrm{CH}-30$ ) and corresponded to the number of mitotic images found in 20 microscopic fields per individual sample, examined with a $\times 40$ objective, as described elsewhere (Morales-González et al, 1999).

\section{Western Blot Analysis for PCNA}

Isolated nuclei (Aguilar-Delfín et al, 1996) from our experimental groups were solubilized in 5\% sodium dodecyl sulfate (SDS, Sigma Chemical Company) and separated on a $12 \%$ SDS-polyacrylamide. Proteins $(100 \mu \mathrm{g})$ were transferred electrophoretically to nitrocellulose filters for 2 hours at a constant current of 330 $\mathrm{mA} / \mathrm{cm}^{2}$, and nonspecific sites were blocked by incubation for 30 minutes at room temperature with PBSbuffered containing 3\% fat-free milk. Then, filters were incubated with polyclonal antihuman cyclin D1 or PCNA antibodies ( $1 \mu \mathrm{g} / \mathrm{ml}$; Upstate, California) overnight at $4^{\circ} \mathrm{C}$, and washed with distilled water (four times). The filters were treated with anti-rabbit-AP antibody. Photographs from filters were quantified using a high resolution color scanner. Rabbit antimouse actin antibody (Calbiochem, La Jolla, San
Diego) was always used as primary antibody to control the amount of loaded protein in each lane.

\section{Immunohistochemical Analysis of PCNA in Liver Nuclei}

Paraffin-embedded sections of rat liver at each time point studied during progression of $\mathrm{PH}$-induced liver regeneration were deparaffinazed with xylene and subjected to antigen retrieval by pretreating for 25 minutes in a microwave at medium power in 0.01 mols/L sodium citrate buffer ( $\mathrm{pH}$ 6.0). Thereafter, samples were sequentially washed with xylene, alcohols, and distilled water, and incubated with $0.01 \%$ Tween-20 in PBS, for 5 minutes. Afterward, specimens were then incubated with peroxidase blocking solution, polyclonal mouse anti-PCNA (diluted 1:100), and horseradish peroxidase-conjugated second antibody contained in a polymer solution, according to the instructions of the manufacturer (Chemicon International Inc., Temeluca, California). Samples were examined under microscopy in high power fields $(\times 40)$, and finally counterstained in Harris' hematoxylin, dehydrated, and mounted. Five independent preparations per experimental group were examined, and representative micrographs were made with an optical microscope (Olympus, $\mathrm{CH}-30$ ).

\section{Calculations and Statistics}

Recovery (gain) of the removed liver mass was calculated according to Diehl et al (1990). All results are expressed as mean \pm SE. Significance of the differences was tested by two-way ANOVA and, in case of significance, a Newman-Keul's test was also applied.

\section{Acknowledgments}

We thank Dr. Omar Medina-Campos for determining $\alpha$-tocopherol content of the biological samples and Ms. María Elena Gutiérrez for secretarial assistance.

\section{References}

Abe J, Kusuhara M, Ulevitch RJ, Berk BC, and Lee J-D (1996). Big mitogen-activated protein kinase I (BMKI) is a redox sensitive kinase. J Biol Chem 271:16586-16590.

Aguilar-Delfín I, López-Barrera F, and Hernández-Muñoz R (1996). Selective enhancement of lipid peroxidation in plasma membrane in two experimental models of liver regeneration: Partial hepatectomy and acute $\mathrm{CCl}_{4}$ administration. Hepatology 24:657-662.

Akira S, Hirano T, Taga T, and Kishimoto T (1990). Biology of multifunctional cytokines: IL- 6 and related IL-1 and TNF. FASEB J 4:2860-2867.

Arora V, Iversen PI, and Ebadi M (1998). Manipulation of metallothionein expression in the regenerating rat liver using antisense oligonucleotides. Biochem Biophys Res Commun 246:711-718.

Awad MM and Gruppuso PA (2000). Cell cycle control during liver development in the rat: Evidence indicating a role for cyclin D1 posttranscriptional regulation. Cell Growth Diff 11:325-334. 
Borrello S, Minotti G, Palombini G, Grattagliano A, and Galleotti T (1985). Superoxide dependent lipid peroxidation and vitamin $\mathrm{E}$ content of microsomes from hepatomas with different growth rates. Arch Biochem Biophys 238:588-595.

Burdon RH and Gill V (1990). Oxidative stress and tumour cell proliferation. Free Rad Res Comms 11:65-76.

Chatelian E, Boscoboinik DO, Bartoli GM, Kagan VE, Gey FK, Packer L, and Azzi A (1993). Inhibition of smooth muscle cell proliferation and protein kinase $\mathrm{C}$ activity by tocopherols and tocotrienols. Biochem Biophys Acta 1176:83-89.

Cheeseman KH, Collins M, Maddix S, Milia A, Proudfoot K, Slater TF, Burton GW, Webb A, and Ingold KU (1986a). Lipid peroxidation in regenerating rat liver. FEBS Lett 209:191196.

Cheeseman KH, Collins M, Proudfoot K, Burton GW, Webb AC, Ingold KU, and Slater TF (1986b). Studies on lipid peroxidation in normal and tumour tissue. The Novikoff rat liver tumour. Biochem J 235:507-514.

Cheeseman KH, Emery S, Maddix S, Slater TF, Burton GW, and Ingold KU (1988). Studies on lipid peroxidation in normal and tumour tissues. The Yoshida rat liver tumour. Biochem $\mathrm{J}$ 250:247-252.

Conway JG, Tomaszewski KE, Olson MJ, Cattley RC, Marsman DS, and Popp JA (1989). Relationship of oxidative damage to the hepatocarcinogenicity of the peroxisome proliferators di(2-ethylhexyl)phthalate and $\mathrm{Wy}-14,643$. Carcinogenesis 10:513-519.

Cressman DE, Greenbaum LE, Haber BA, and Taub R (1994). Rapid activation of posthepatectomy factor/nuclear factor kappa $B$ in hepatocytes, a primary response in the regenerating liver. J Biol Chem 269:30429-30435.

Diehl AM, Wells M, Brown N, Thorgeirsson SS, and Steer CJ (1990). Effect of ethanol on polyamine synthesis during liver regeneration in rats. J Clin Invest 85:385-390.

Factor VM, Laskowska D, Jensen MR, Woitach JT, Popescu NC, and Thorgeirsson SS (2000). Vitamin E reduces chromosomal damage and inhibits hepatic tumor formation in a transgenic mouse model. Proc Natl Acad Sci USA 97:21962201.

Fukuhara K, Suzuki M, Unno M, Masihur-Rahman M, Endo K, and Matsuno $S$ (1999). The degree of hepatic regeneration after partial hepatectomy in rats with peritonitis and the role of lipid peroxidation. Free Rad Biol Med 26:881-886.

Gavino VC, Dillard CJ, and Tappel AL (1985). Effect of dietary vitamin $E$ and santoquin on regenerating rat liver. Life Sci 36:1771-1777.

Gavino VC, Miller JS, Ikharebha SO, Milo GE, and Cornwell DG (1981). Effect of polyunsaturated fatty acids and antioxidants on lipid peroxidation in tissue cultures. J Lipid Res 22:763-769.

Guerrieri F, Pellecchia G, Lopriore B, Papa S, EsterinaLiquori G, Ferri D, Moro L, Marra E, and Greco M (2002). Changes in ultrastructure and the occurrence of permeability transition in mitochondria during rat liver regeneration. Eur J Biochem 269:3304-3312.

Guerrieri F, Vendemiale G, Grattagliano I, Cocco T, Pellecchia G, and Altomare E (1999). Mitochondrial oxidative alterations following partial hepatectomy. Free Rad Biol Med 26:34-41.
Hammad H, Higashi T, Tateishi N, Hanatani N, and Sakamoto $Y$ (1990). Lipid peroxidation in the liver of carcinogenresistant rats. Biochim Biophys Acta 1045:99-106.

Hernández-Muñoz R, Díaz-Muñoz M, López V, LópezBarrera $F$, Yáñez $L$, Vidrio $S$, Aranda-Fraustro $A$, and Chagoya de Sánchez V (1997). Balance between oxidative damage and proliferative potential in an experimental rat model of $\mathrm{CCl}_{4}$-induced cirrhosis: Protective role of adenosine administration. Hepatology 26:1100-1110.

Hernández-Muñoz R, Montiel-Ruíz C, and Vázquez-Martínez O (2000). Gastric mucosal cell proliferation in ethanolinduced chronic mucosal injury is related to oxidative stress and lipid peroxidation in rats. Lab Invest 80:1161-1169.

Hernández-Muñoz R, Sánchez-Sevilla L, Martínez-Gómez A, and Dent MAR (2003). Changes in mitochondrial adenine nucleotides and in permeability transition in two models of rat liver regeneration. Hepatology 37:842-851.

Higgins GM and Anderson RM (1931). Experimental pathology of the liver. Arch Pathol 12:186-202.

Huang CJ and Shaw HM (1994). Tissue vitamin E status is compromised by dietary protein insufficiency in young growing rats. J Nutr 124:571-579.

Kunisaki M, Bursell SE, Clemont AC, Ishii H, Ballas LM, Jirousek MR, Umeda F, Nawata H, and King GL (1995). Vitamin $\mathrm{E}$ prevents diabetes-induced abnormal retinal flow via the diacylglycerol-protein kinase $\mathrm{C}$ pathway. Am J Physiol 269:E239-E246.

Lambotte L, d'Udekem Y, Lambert F, Gressens P, Amrani M, and Dubois $J$ (1989). Possible role of free radicals in liver regeneration. Adv Biosci 76:177-185.

Laurent S, Otsuka M, De Saeger C, Maiter D, Lambotte L, and Horsmans $Y$ (2001). Expression of presumed specific early and late factors associated with liver in different rat surgical models. Lab Invest 81:1299-1307.

Mao-Hua M, Wei A, Bao-Hong Z, Qing S, and De-Zheng G (1993). Hepatic stimulator substance protects against acute liver failure induced by carbon tetrachloride poisoning in mice. Hepatology 17:638-644.

Masotti L, Casali E, and Galeotti T (1988). Lipid peroxidation in tumor cells. Free Rad Biol Med 4:377-386.

Morales-González JA, Gutiérrez-Salinas J, Yáñez L, Villagómez-Rico C, Badillo-Romero J, and HernándezMuñoz R (1999). Morphological and biochemical effect of a low ethanol dose on rat liver regeneration. Role of route and timing of administration. Dig Dis Sci 44:1963-1974.

Oikawa I and Novikoff PM (1995). Catalase-negative peroxisomes: Transient appearance in rat hepatocytes during liver regeneration after partial hepatectomy. Am J Pathol 146:673-687.

Pibiri M, Ledda-Columbano GM, Cossu C, Simbula G, Menegazzi M, Shinozuka H, and Columbano A (2001). Cyclin D1 is an early target in hepatocyte proliferation induced by thyroid hormone. FASEB J 15:1006-1013.

Ricciarelli R, Tasinato A, Clément S, Ozer NK, Boscoboinik D, and Azzi A (1998). $\alpha$-Tocopherol specifically inactivates cellular protein kinase $\mathrm{C} \alpha$ by changing its phosphorylation state. Biochem J 334:243-249.

Ruff-Jamison S, Zhong Z, Wen Z, Chen K, Darnell JE, and Cohen S (1994). Epidermal growth factor and lipopolysasac- 
charide activate STAT 3 transcription factor in mouse liver. J Biol Chem 269:21933-21935.

Schreck R and Baeuerle PA (1991). A role for oxygen radicals as second messengers. Trends Cell Biol 1:39-42.

Slater TF, Cheeseman KH, Benedetto Ch, Collins M, Emery S, Maddix SP, Nodes JT, Proudfoot K, Burton GW, and Ingold KU (1990). Studies on the hyperplasia ("regeneration") of the rat liver following partial hepatectomy. Biochem $\mathrm{J}$ 265:51-59.

Spinella MJ, Freemantle SJ, Sekula D, Chang JH, Christie AJ, and Dmitrovsky E (1999). Retinoic acid promotes ubiquitination and proteolysis of cyclin D1 during induced tumor cell differentiation. J Biol Chem 274:22013-22018.

Tanaka T, Goto Y, Imano M, Asai H, Yamada T, Kawai S, Kunitoh S, Kondo K, Yamashita T, Monna T, Nishiguchi S, Kuroki K, and Otani S (1996). Effect of vitamin E deficiency on inhibition of liver regeneration by long-term administration of ethanol. Alcohol Clin Exp Res 20(Suppl 1):47A-50A.

Taub R (1998). Blocking NF- $\kappa$ B in the liver: The good and bad news. Hepatology 27:1445-1446.

Toyonuki S, Okamoto K, Yodoi J, and Hiai H (1995). Persistent oxidative stress in cancer. FEBS Lett 358:1-3.
Tsai JL, King KL, Chang CC, and Wei JH (1992). Changes of mitochondrial respiratory functions and superoxide dismutase activity during liver regeneration. Biochem Int 28: 205-217.

Ueda K, Yoshioka T, Takehara Y, and Abe K (1983). Lipoperoxides, vitamin $\mathrm{E}$, and activities of superoxide dismutase, glutathione peroxidase, and catalase in regenerating rat liver. Biochem Int 7:663-669.

Wolfson N, Wilbur KM, and Bernheim F (1956). Lipid peroxide formation in regenerating liver. Exp Cell Res 10:556-558.

Yamada Y, Kirillova I, Peschon JJ, and Fausto N (1997). Initiation of liver growth by tumor necrosis factor: Deficient liver regeneration in mice lacking type I tumor necrosis factor receptor. Proc Natl Acad Sci USA 94:1441-1446.

Yang KC, Li X, and Tsui ZC (1989). The relationship between nutritional antioxidants and serum lipid peroxides in cancer patients. In Vivo 3:211-214.

Ye H, Kelly TF, Samadani U, Lim L, Rubio S, Overdier DG, Roebuck KA, and Costa RH (1997). Hepatocyte nuclear factor 3 /fork head homolog 11 is expressed in proliferating epithelial and mesenchymal cells of embryonic and adult tissues. Mol Cell Biol 17:1626-1641. 